\title{
AN EXPLORATORY STUDY OF EXPECTED BUSINESS VALUE OF CLOUD COMPUTING
}

\author{
Ta-Tao Chuang, Gonzaga University, chuang@jepson.gonzaga.edu \\ Kazuo Nakatani, Florida Gulf Coast University, knakatan@fgcu.edu \\ Thoma Teming Chen, Global ECommerce Service, Inc., tmchen@globalecsi.com
}

\begin{abstract}
The purpose of the study is to gain an understanding of expected benefits and to clarify relevant issues of cloud computing. The study conducted a survey on businesses of different sizes in Taiwan and five hypotheses were tested. The expected benefit of cloud computing was measured in three dimensions: cost reduction, increased capability and enhanced scalability. The data analysis results show that businesses expect greater benefit of cloud computing than that of traditional computing. Also, the expected benefit varies from one type of cloud computing service to another. Nevertheless, businesses' expectation of cloud computing benefit doesn't change from one area of the value chain to another. The data did not support the hypothesis that the firm size might affect the expected benefit of cloud computing. This suggests that cloud computing might level the playing field for small-and medium-sized enterprises (SMEs) to gain the same advantage as that large companies can.
\end{abstract}

Keywords: Cloud Computing, SaaS, PaaS, IaaS, Expected Business Benefits

\section{INTRODUCTION}

Cloud computing has obtained a great deal of attention as a cost effective alternative to the traditional on premise information systems sourcing option. A study by International Data Corporation shows that worldwide spending on public cloud services is expected to be more than $\$ 107$ billion in 2017 [18]. Although many research reports and white papers [e.g. 17, 19, 22, 27, 35] claim that cloud computing can bring substantial benefits for businesses such as dramatically reduced upfront costs of computing, rapid deployment and scalability, and delivery of new value for customers through innovative applications along the value-chain, empirical studies regarding business benefits of cloud computing in the information systems field are sporadic [27]. Among the limited studies, contradictory findings have been reported. For example, different from general claims, [23] finds that cost savings from cloud computing can be realized by new companies only although previous literature suggests that cloud computing can help companies, especially SMEs, to make savings from buying, running, and maintaining their IT infrastructure. Besides, [27] indicates that the cost saving benefit of cloud computing varies across businesses of different sizes. [27] furthers that from the competitive advantage perspective, cloud computing may enable businesses to create values through innovative applications along the value-chain. Nevertheless, no empirical studies support such assertions.

The purpose of the research is to empirically explore the impact of contextual factors on businesses' expectation of the benefit of cloud computing with a goal in mind that the findings will provide empirical basis for decision makers who are planning to adopt cloud computing. Specifically, the first research objective is to examine the difference in benefit between cloud computing and conventional on premise information services. The second objective is to study how the service type of cloud computing affects the level of benefit expected by businesses. The third and fourth research objectives are to analyze whether or not businesses' expectation of the benefit of cloud computing varies in different value chain activities and in different size of enterprises, respectively.

This research contributes to academics by providing research findings from empirical data about benefits of cloud computing. Additionally, the research provide empirical data about what kind of benefits are recognized and who recognizes those benefits.

This research can also be beneficial to practitioners by finding answers to some of the questions raised by [27] for business professionals. First, by identifying which value chain activities can benefit most from cloud computing, the 
research findings help to identify which area of supply chain to employ cloud computing. And, by understanding the impact of the firm size on the expected benefit of cloud computing, the research provides the basis on which companies can determine whether to adopt cloud computing. Also, the research helps cloud service providers recognize where their focus should be on to convince prospective customers (SMEs or large businesses) to switch from the traditional on premise options to cloud computing in either the primary or support value chain activities.

\section{BUSINESS BENFITS OF CLOUD COMPUTING}

This section discusses business benefits of cloud computing reported by previous research studies. They are discussed in three areas: Cost savings, IT/Business capability improvement, and Scalability, elasticity or resource adjustment.

\section{Cost Savings}

Cloud computing has a great impact on business costs, facilitating its diffusion [32]. Businesses can save costs in several ways from cloud computing. One of the most recognized cost saving is less or often zero upfront investment in hardware and software as the traditional on premise data center has to purchase and implement hardware and software while cloud applications and infrastructure are pay-per-use $[2,3,6,9,14,16,22,23,29,34,37]$. This allows businesses to shift investment in IT from capital expenditure to operation expenses $[8,9,13,19,35]$.

Also, several studies reported cost savings in operations, maintenance and upgrade as benefits of cloud computing $[6,14,16,20,24,27,29,34]$. Cloud computing uses multi-tenancy to share the application instances and hardware and thus consolidates hardware to save costs, achieving economies of scale [31]. Because of this, cloud computing can provide services of IT operations, business continuity and security efficiently and thus the operation cost of cloud computing is often lower than that of the on premise option [14]. [20] reported that there were many different reasons for businesses to migrate from the traditional on premise option to cloud computing, but the most important factor is reduction in costs, especially lowering total cost of ownership, although [4] found that the total cost of executing highly complex applications in the cloud could be higher than that incurred by executing them in a private data center, while in the case of less complex application leasing proved to be more favorable. Businesses can also save costs because, due to cloud computing's "pay as you go" pricing model, they don't have to buy new hardware in order to meet increased demand [2]. Cloud computing also allows businesses to reduce IT personnel costs, especially in Software as a Service (SaaS). In-house IT team may not be necessary or can be minimized especially in SaaS because no hardware and software installation is required and because IT department does not control the data and system [7]. Also, cloud computing reduces the number of employees needed to maintain systems and develop software [25]. Finally, [9] reported that less or zero initial cost of acquiring IT infrastructure reduces the entry barrier especially for SMEs.

\section{Improved IT and Business Capability}

Several studies reported that cloud computing provided improved and new capability that could not be provided by the traditional on premise option $[14,35]$. These improved and new capabilities include the deployment speed of IT resources, quicker corporate response to consumer needs by customizing computing resources for business needs, concentrating on core competency, improved efficiency of information processing operations, and interoperability between different computing resources that facilitates sharing and collaboration.

In cloud computing, IT resources can be deployed immediately or very quickly $[8,21,27,35]$. This is mainly because cloud computing, especially SaaS, does not require purchase, installation and configuration of hardware and software. [16] reported that SaaS benefits included faster delivery of application features, improved support for remote users and better overall user satisfaction via familiar web user interfaces. Even Platform as a Service (PaaS) offers a development environment that makes the application development and deployment faster because it eliminates the wait for deployment of suitable hardware and software for the applications [23].

[17] stated that cloud computing allowed a business to respond quickly to customer needs in a far more costeffective manner. Applications in the cloud could be modified on a daily base, which is impossible with the on 
premise solutions [9]. [27] reported that cloud computing helped businesses to bring products or services to the market faster and lower IT barriers to innovation.

Several studies mentioned that cloud computing could be used to create competitive advantage [27,33]. According to [12], many IT expenditure costs don't directly contribute to business growth; eighty percent of business expenditure in IT is called "dead money", which is used for maintaining existing systems, rather than an upgrade. Cloud computing allows business to concentrate on its core competencies by allowing capital to be redirected to core business investment $[2,6,11,13]$. [27] claimed that cloud computing allowed smaller firms to benefit from compute-intensive business analytics or new classes of applications that were available only to large corporations, creating new business capabilities.

Cloud computing speeds up processing time [2] because businesses can access more powerful hardware in cloud computing than in the traditional on premise option. Especially, SMEs can access high capacity IT infrastructure via cloud computing that only large companies can afford. According to [25], renting a server in the cloud costs approximately one-third of the expense of buying and maintaining similar equipment. It is possible to acquire IT capacities that businesses may not have been able to afford in the past [14].

Finally, [19] reported that significant benefits of cloud computing for the enterprise included resource access, collaboration, and customization. According to [15], large enterprises perceived improved sharing and collaboration as benefits of cloud computing.

\section{Scalability, Elasticity, or Resource Adjustment Capability}

The third benefit of cloud computing reported by several studies is scalability or elasticity, which means a capability to adjust IT resources as the business need changes [2, 3, 8, 10, 11, 14, 19, 22, 23, 31, 35].

Compared with the traditional IT solutions, cloud computing offers clear advantages such as dynamically scalable IT capabilities that allow users to adjust their usage of IT services as and when required $[3,14,23]$. Companies are reluctant to maintain IT resources that are needed at the peak time because those resources are idle in other time. However, if they don't, it may cause customer dissatisfaction and dissatisfied customers are likely not to come back [2].

Cloud computing can make resources available on demand quickly enough as if it has infinite capacity, which eliminates the need for capacity planning [2]. Especially, SMEs can take advantage of this capability, eliminating the up-front commitment, starting small and expanding computing resources only when necessary $[2,11]$. Cloud hosted applications allow business to react faster to sudden changes in demand [31].

\section{RESEARCH METHOD}

The research method of the study is the survey research. The measurement instrument is a questionnaire consisting of 15 items with a 5-point Likert scale. The subject companies are those in Taiwan that plan to adopt cloud computing. Per our research objectives, we develop a research model as shown in Figure 1. 


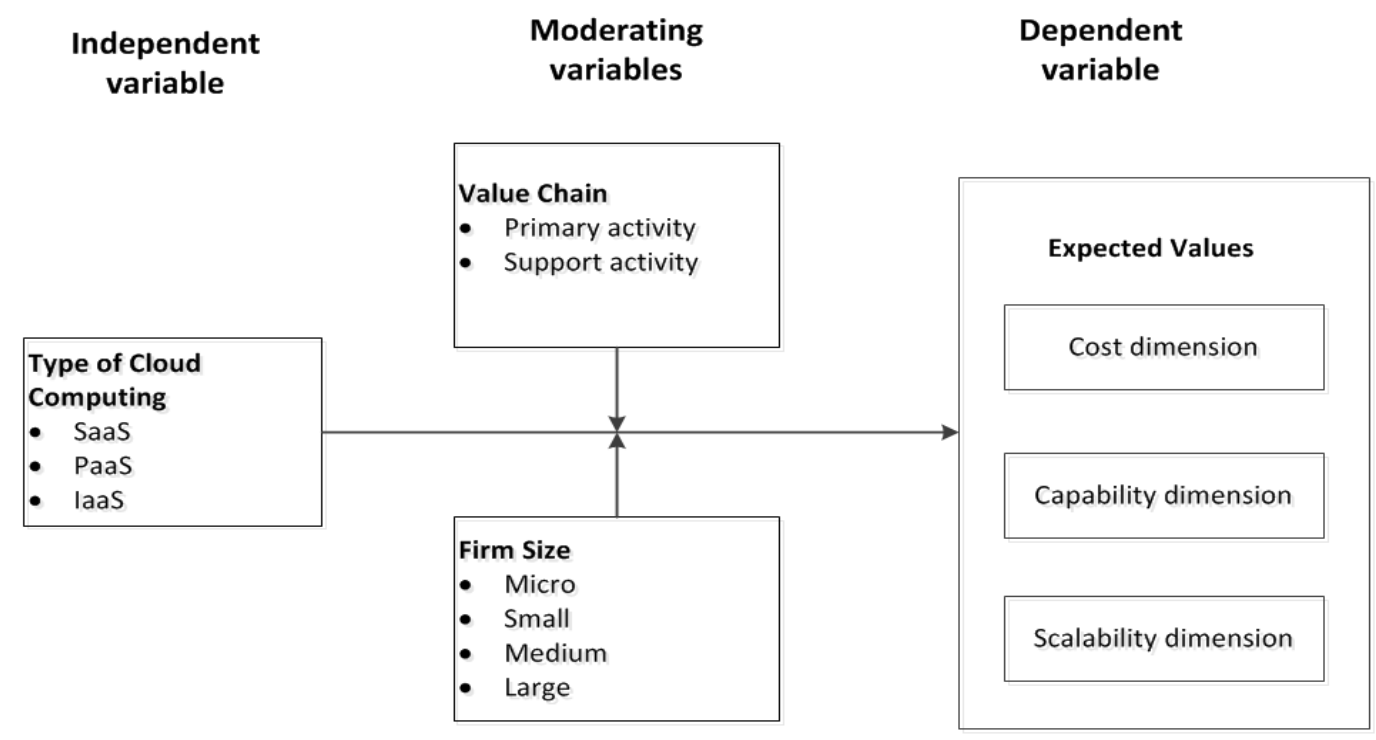

Figure 1. Research Model

The main proposition of the study is: Businesses expect that the benefit of cloud computing varies across different types of cloud computing and the expected benefit is moderating by the area of the value chain where it is adopted and the firm size.

\section{Research Hypotheses}

It has been asserted that cloud computing offers many advantages over the traditional on premise model of IT services, such as decapitalization, easy accessibility, scalability and cost-effectiveness $[8,19,22]$. It appears reasonable to infer that businesses would switch from the traditional on premise model to cloud computing if and only if they expect the benefit of cloud computing is greater than that of the traditional on premise model. Thus, we formulate the first hypothesis as follow:

$\mathrm{H}_{1}$ : Businesses expect greater benefit of cloud computing than that of traditional on premise model of IT services.

There are three types of cloud computing services: Software as a Service (SaaS), Platform as a Service (PaaS), and Infrastructure as a Service (IaaS) [e.g. 7, 11, 15, 23, 26, 28, 30, 32, 33, 37, 38, 39] although some offer additional more fine grained services $[1,5]$. SaaS allows users to use the provider's applications running on a cloud infrastructure [28]. PaaS allows the customers to deploy software they developed or acquired on the cloud infrastructure [28]. Also, PaaS provides users with software development, testing, deployment, monitoring, and hosting environment [38]. IaaS makes the IT hardware infrastructure (such as servers, storage devices, computing power, etc.) available to end users through the Internet. IaaS provides processing, storage, networks, and other fundamental computing resources so the customers of IaaS can deploy any operating systems and application software they want without managing the underlying hardware infrastructure [28].

These three types of cloud computing services form a hierarchical structure from most direct to least direct, SaaS, PaaS, and IaaS, respectively, in terms of the relationship between the user and cloud computing [38]. Since IaaS provides computing infrastructure, such as storage, network and data center, in general, it is not directly relevant to the user's job. In contrast, SaaS provides application tools that might be tailored for the user and thus, it is the most directly relevant to the user's job. The relevance of PaaS to the user is between SaaS and IaaS. A logical inference following the reasoning is that since some types of cloud computing are more relevant to the user's jobs, the user might expect greater benefit from those types than others. Thus, the expected benefit of SaaS should be greater than that of IaaS and the expected benefit of PaaS should between those of SaaS and of IaaS. This study thus proposes research hypothesis $\mathrm{H}_{2}$ as follow. 
$\mathrm{H}_{2}$ : Businesses expect that different types of cloud computing would produce different benefit of cloud computing. According to Porter's Value Chain Analysis Model [36], a business can analyze its activities and identify activities that add most values to their products and service, and then form a proper competitive strategy. Using IT to support and strengthen those value-adding activities could help the execution of the competitive strategy, and potentially change the landscape of competition. The primary activities of the value chain are directly related to revenue generation, whereas the support activities are supporting implementation of the main activities. Therefore, in theory, assuming everything else is equal, an informed business would expect more benefit of cloud computing services when they are used to strengthen the primary activities than that when they are used in the support activities. Nevertheless, it should be noted that different activities of the value chain may need different amounts and kinds of IT supports. For example, legal affair, which is one of the support activities in most companies except for law firms, needs computing service that is more of an infrastructure, such as IaaS, than that of intensive computing capability such as SaaS. In other words, the impact of the value chain activities on the benefit of cloud computing could be moderated by the type of cloud computing service. Based on the reasoning, we propose research hypotheses $\mathrm{H}_{3}$ and $\mathrm{H}_{4}$.

$\mathrm{H}_{3}$ : Businesses expect that cloud computing services applied in different categories of the value chain activities would produce different benefits.

$\mathrm{H}_{4}$ : Businesses expect that the benefit of cloud computing in different categories of the value chain activities would be different among different types of cloud computing.

According to the resource-based view of competitive advantage, large enterprises are more likely to enjoy the advantage that traditional on premise model of IT brings about than SMEs. The traditional on premise model of IT is relatively costly. Large enterprises are generally more resourceful than SMEs. Thus, large enterprises can assume greater risk and are more willing to invest in new technologies than SMEs. As a result, in the era of traditional on premise model of IT, large enterprises more likely have the advantage of IT than SMEs does.

Nevertheless, cloud computing owns features that may level the playing field. The difference between cloud computing and traditional on premise model of IT services lies in that the former provides the feature of pay per use without costly initial investment. Such a feature enables resource strapped SMEs to obtain the right amount of IT resources and gain similar advantage as large enterprises do. Thus, one interesting question is: Does the firm size affect the expected benefit of cloud computing? We formulate hypotheses $\mathrm{H}_{5}$ and $\mathrm{H}_{6}$ to examine the impact of firm size on the expected benefit of cloud computing as follows:

$\mathrm{H}_{5}$ : Businesses of different sizes expect benefit of cloud computing differently.

$\mathrm{H}_{6}$ : Businesses of different sizes expect that different types of cloud computing produce different benefits.

\section{Operational Definition of Research Variables}

The independent variable of the study is the type of cloud computing, which has three levels as defined by the US NIST [28]: Software as a Service (SaaS), Platform as a Service (PaaS), and Infrastructure as a Service (IaaS). The dependent variable, the expected benefit of cloud computing, is measured with three indicators compiled from existing literature: business costs saving, improved business capabilities, and enhanced business scalability. Cost saving includes all of savings that businesses expect to accrue by using cloud computing, such as saved initial investment, reduced overall operating costs, maintenance costs, and replacement costs. Expected improved business capabilities include information processing capability, ability to meet customer-specific requirements, resource deployment capability, interoperability, and business responsiveness. Expected enhanced business scalability includes flexibility of resources sharing, flexible computing resources, operations management flexibility, flexible recovery operation, and reliability adjustment.

One moderating variable, the value chain activity, has nine levels as the same as the sub-categories of Porter's value chain analysis [36]: in-bound logistics, production operations, out-bound logistics, marketing and sales, service after the sale, which are the primary activities and human resource management, technology development, procurement, and enterprise infrastructure, which are the support activities. Each sub-category is measured with specific activities performed by businesses. 
The other moderating variable, the firm size, is measured with the number of employees. The concept of categorization of firm size in terms of the number of employees is relative, varying from country to country. We classify the firm size into four categories: micro, small, medium, and large. Micro-businesses have 10 employees or less, small businesses have 11 to 50 employees, medium-sized businesses have 51 to 200 employees, and large businesses have 200 employees or more. This classification is based on the standards in the SME Development Act defined by the Ministry of Economic Affairs of Taiwan.

\section{Questionnaire Design}

Based on existing literature, we developed the measurement instrument of this study. The questionnaire was revised several times for the face validity. Five practitioners and academics were invited to review and pre-test for semantic clarity and content validity. The questionnaire consists of two parts: The first part collects data of business type, the number of employees, the type of cloud computing to be deployed and the area of the value chain where the cloud computing service to be deployed. The second part consists of 15 items of a five-point Likert scale, measuring expected cost savings, expected improved business capabilities and expected enhanced business scalability.

\section{Population and Sample}

The subject population of the study is companies that are registered in Taiwan and have capital of TWD $\$ 500,000$ or more. The sampling frame consists of four sources: Directory of Hi-Tech Promotion Center (Department of Economic Development, Taipei City Government), The Statistics for Taipei City Firms and Corporations Registration (Taipei City Office of Commerce), Directory of Nankang Software Park Website and Business Registration Directory of Department of Commerce (MOEA). Random sampling from the sample frame produced a sample of 7000 companies, which were invited to participate in the survey via postal mails. After excluding invalid responses, the study obtained 147 useful questionnaires. Additionally, via an electronic survey, we further collected 230 useful responses. In total, the study obtained 377 valid responses.

\section{DATA ANAYSIS}

SPSS 20 was used to analyze the data. The descriptive statistics of the data are shown in Table 1 below.

Table 1. Descriptive Statistics of Subject Companies

\begin{tabular}{lcclcc}
\hline \multicolumn{1}{c}{ Industry } & $\mathbf{n}$ & $\mathbf{\%}$ & \multicolumn{1}{c}{ Industry } & $\mathbf{n}$ & $\mathbf{\%}$ \\
\hline Financial and banking & 9 & 2.4 & Manufacturing & 102 & 27.1 \\
Financial planning & 6 & 1.6 & Law & 2 & $<1.0$ \\
Healthcare and cosmetic & 9 & 2.4 & Biochemistry & 8 & 2.1 \\
Construction & 18 & 4.8 & Educational & 12 & 3.2 \\
IT and Communication & 39 & 10.3 & Transportation & 10 & 2.7 \\
Wholesaler & 17 & 4.5 & Real estate & 7 & 1.9 \\
Insurance & 4 & 1.1 & Business service & 34 & 9.0 \\
Public Utility & 7 & 1.9 & Warehousing & 1 & $<1.0$ \\
Leisure and entertainment & 5 & 1.3 & Photoelectric & 18 & 4.8 \\
Retailing & 19 & 5.0 & Others & 50 & 13.3 \\
\hline Number of employees & $\mathbf{n}$ & $\mathbf{\%}$ & Type of Cloud Computing & $\mathbf{n}$ & $\mathbf{\%}$ \\
\hline Less than 10 & 132 & 35.0 & SaaS & 105 & 27.9 \\
11 50 & 120 & 31.8 & PaaS & 96 & 25.5 \\
51 200 & 59 & 15.6 & IaaS & 176 & 46.7 \\
More than 200 & 66 & 17.5 & & & \\
\hline Value Chain & $\mathbf{n}$ & $\mathbf{\%}$ & & & \\
\hline Primary activity & 222 & 59.9 & & & \\
Support activity & 155 & 41.1 & & &
\end{tabular}




\section{Reliability and ANOVA}

The reliability coefficient (Cronbach alpha) of the scale for benefit of cloud computing is 0.872 , indicating a high reliability. The internal consistency coefficients of the three indicators of benefits of cloud computing are 0.811 , 0.754 , and 0.827 , respectively, within the acceptable range.

One sample t-test is used to test hypothesis $\mathrm{H}_{1}$, businesses expect greater benefit of cloud computing than that of traditional on premise model of IT services. The test is significant at the significance level of 0.05 , as shown below.

Table 2-1. One Sample Statistics

\begin{tabular}{lcccc}
\hline & $\mathbf{N}$ & Mean & Std. Deviation & Std. Error Mean \\
\hline Expected benefit & 377 & 3.6286 & .57725 & .02973 \\
\hline
\end{tabular}

Table 2-2. One Sample Test (Test Value =3)

\begin{tabular}{ccccccc}
\hline & $\mathbf{t}$ & df & $\begin{array}{c}\text { Sig. } \\
\text { (2-tailed) }\end{array}$ & $\begin{array}{c}\text { Mean } \\
\text { Difference }\end{array}$ & $\begin{array}{c}\text { 95\% Confidence Interval of the Difference } \\
\text { Lower }\end{array}$ & Upper \\
\hline Expected benefit & 21.145 & 376 & .000 & .62865 & .5702 & .6871 \\
\hline
\end{tabular}

To examine the effect of independent variable on the dependent variables, MANOVA was employed. As the nature of the study is explorative, Wilks' lambda $\alpha$ value was set at 0.1 for significant test. For post-hoc tests, the RoyBargmann Stepdown Analysis method was used to reduce the probability of type one error.

The results of MANOVA analysis show that hypothesis $\mathrm{H}_{2}$ is supported at the significance level of 0.1 . That is, hypothesis $\mathrm{H}_{2}$, different types of cloud computing have different expected benefits, is supported with $\mathrm{F}(6,738)=$ $2.322, \mathrm{p}<0.05$. The result shows that businesses expect different amounts and kinds of benefits from different types of cloud computing. Further analysis of what causes the difference shows that the difference in expected benefit between different types of cloud computing can be attributed to difference in the dimensions of capability and scalability. In these two dimensions, the expected benefits of SaaS and IaaS are higher than those of PaaS.

On the contrary, the data fails to support hypothesis $\mathrm{H}_{3}$, the expected benefits of cloud computing applied in different categories of the value chain activities are different, at the significance level of 0.1 . The effect of the value chain activities on the expected benefit of cloud computing is not significant, $F(3,369)=1.583$, $p>0.1$. In other words, businesses planning to adopt cloud computing don't expect difference in benefit of cloud computing between different value chain activities. Nevertheless, further analysis of the interaction effect of types of cloud computing and categories of the value chain activities is significant, $\mathrm{F}(6,738)=2.612, \mathrm{p}<0.05$. The result warrants a further analysis of expected benefits of different types of cloud computing in different categories of the value chain activities.

Further analysis of the interaction effect of the type of cloud computing and the area of the value chain activities shows that SaaS has greater expected benefit in cost saving than IaaS does, IaaS has greater expected benefit in capability than PaaS does, and Saas and IaaS have greater expected benefit in scalability than PaaS does. Additionally, the impact of the value chain activities on expected benefit is significant in the type of SaaS only: the expected benefit of cost saving in the primary activities is greater than that in the support activities, while expected benefit of improved capability in the support activities is greater than that in the primary activities.

The result of MANOVA analysis shows that the data fails to support hypothesis $\mathrm{H}_{5}$, businesses of different sizes expect the benefit of cloud computing differently. The hypothesis test is not significant at the significance level of $0.1, \mathrm{~F}(6,726)=0.870, \mathrm{p}>0.1$. Also, the interaction effect of the firm size and the type of cloud computing is not supported, $\mathrm{F}(18,1027)=1.349, \mathrm{p}>0.1$.

In summary, hypotheses H1, H2, and H4 are supported, while hypotheses H3, H5 and H6 are not supported, as summarized in Table 3. 
Table 3. Summary of Hypothesis Testing

\begin{tabular}{llc}
\hline & \multicolumn{1}{c}{ Hypotheses } & Results \\
\hline H1 & $\begin{array}{l}\text { Expected benefit of cloud computing is greater than that of traditional on premise } \\
\text { model of IT services }\end{array}$ & Supported \\
\hline H2 & $\begin{array}{l}\text { Businesses expect that different types of cloud computing produce different } \\
\text { benefit of cloud computing }\end{array}$ & Supported \\
\hline H3 & $\begin{array}{l}\text { Businesses expect that cloud computing services applied in different categories of } \\
\text { the value chain activities would produce different benefits }\end{array}$ & Fail to support \\
\hline H4 & $\begin{array}{l}\text { Businesses expect that the benefit of cloud computing in different categories of the } \\
\text { value chain activities would be different among different types of cloud computing }\end{array}$ & Supported \\
\hline H5 & Businesses of different sizes expect benefit of cloud computing differently & Fail to support \\
\hline H6 & $\begin{array}{l}\text { Businesses of different sizes expect that different types of cloud computing } \\
\text { produce different benefits }\end{array}$ & Fail to support \\
\hline
\end{tabular}

\section{Discussions}

The results of the study show that businesses expect cloud computing to have greater benefit than traditional on premise model of IT (H1), which confirms claims made by the proponents of cloud computing. Nevertheless, it should be noted that although extant literature suggests that one major benefit of cloud computing is to reduce the cost of IT and business operations, the results of the study show that the expected benefits of improved capability and enhanced scalability are greater than cost saving. Whether cloud computing truly brings greater benefits in these two dimensions needs further investigation; nevertheless, the finding has significant practical implication to cloud computing providers that businesses' expectation of cloud computing is beyond cost saving and providers need to provide more sophisticated features of cloud computing services.

The finding also has interesting implications for academics. Cost saving that cloud computing brings about has been an advantage widely claimed by textbooks, press, and white papers. It would be very interesting to investigate why the findings of the study suggest differently. One possible explanation for the finding is that cloud computing is a relatively new technology and its introductory investment or conversion cost is still relatively high, thus, in the short term, the cost saving might not be easily realized, whereas the elasticity of cloud computing may immediately make businesses more capable or scalable.

Hypothesis $\mathrm{H} 2$ that different types of cloud computing produce different expected benefits is supported. Combining this finding with the result of post-hoc analysis of H1 shows that in terms of improved capability and enhanced scalability, companies expect more from using SaaS or IaaS than from PaaS type. In other words, in terms of their relevance to the user, SaaS, PaaS and IaaS comprise a hierarchical structure [38], but the expected benefits of the three types of cloud computing do not present similar structure. One possible explanation is that PaaS provides a development platform, which is less relevant to the user's tasks.

Although hypothesis $\mathrm{H} 3$ is not supported by the data, it is noteworthy that further analysis of comparison between different dimensions of expected benefits of cloud computing suggests that when applied in the area of primary activities, different types of cloud computing have different amounts and/or kinds of benefits (H4). In terms of cost saving, businesses expect SaaS to be more beneficial than PaaS and IaaS. In terms of improved capability, IaaS is viewed by businesses more efficient than SaaS and PaaS. As for the expected benefit of enhancing scalability, SaaS and IaaS are viewed by businesses to produce more benefit than PaaS. In other words, a business that plans to apply cloud computing in the primary activities of the value chain and wants to gain the benefit of cost saving may tend to adopt SaaS. Those that want to improve capability might tend to adopt IaaS, while those that want to enhance scalability may tend to adopt SaaS or IaaS.

Businesses expect that SaaS may produce more benefit in the primary activities than in the support activities. This is an interesting finding. Since the primary activities (inbound logistics, operation, outbound logistics, marketing and after-sales service) are directly related to revenue generation, businesses should have expected SaaS to create more values rather than to save cost. One possible explanation is that most companies in Taiwan adopt a low cost 
leadership as their competitive strategy, as a result, they also expect the main benefit of cloud computing to be cost saving.

The data fails to support hypothesis H5 that businesses of different sizes expect benefit of cloud computing differently. This is a very interesting finding because extant literature strongly support the proposition that the firm size is an influential factor of IT adoption. One possible explanation is that the features of cloud computing, such as low cost, decapitalization, and elasticity, truly level the playing field so that SMEs have the same expectation as large companies.

\section{CONCLUSIONS AND LIMITATIONS OF THE STUDY}

The benefit of cloud computing has been broadly discussed, while empirical research in academics has been sporadic. The study is intended to examine "claimed" benefits of cloud computing from potential users' perspective. Based on extant literature and our observations, we propose a research model that consists of the type of cloud computing as independent variable, expected benefit of cloud computing as dependent variable, the firm size and the category of the value chain activities as moderating variables. The study is exploratory in nature. The main proposition of the study is that businesses would expect different amounts and kinds of benefit from different types of cloud computing. Also, the relationship between the type of cloud computing and its benefit is moderated by the firm size and the area of the value chain where cloud computing is used. Based on the research model and the proposition, six hypotheses are formulated.

The results of the study show that the expected benefit of cloud computing is greater than that of traditional on premise model of IT services. Second, businesses that plan to adopt cloud computing expect different amounts and kinds of benefit from different types of cloud computing. Third, a "time-tested" finding that the firm size is an influential factor of IT adoption and use is not supported in the study. This is an interesting finding because it may imply that cloud computing might truly give SMEs tools to gain the same advantage as what traditional IT provides large companies.

The findings of the study should be interpreted with the research limitation in mind. First of all, the survey research method with simple random sampling is used in the study. The subjects volunteered to return the questionnaire. Thus, the bias of self-selection might affect the generalization of the findings. Second, the data is cross-sectional and doesn't show changes in businesses' expectation over time. Third, the sample of subject companies is those in Taiwan where most companies are SMEs and those companies' mind set of competitive strategy might affect their expectation of benefit and how they would use cloud computing. Nevertheless, the results of the study present several interesting findings that deserve attention from academics and practitioners and warrant further research.

\section{REFERENCES}

1. Ahson, S., \& Ilyas, M. (2011). Cloud Computing and Software Services: Theory and Techniques. Boca Raton, FL: CRC Press.

2. Armbrust, M., Fox, A., Griffith, R., Joseph, A. D., Katz, R., Konwinski, A., Lee, G., Patterson, D., Rabkin, A., Stoica, I., and Zaharia, M. (2010). A View of Cloud Computing. Communications of the ACM, 53 (4), pp. 5058.

3. Barnatt, C., 2010. A Brief Guide to Cloud Computing, Robinson, London.

4. Brumec, S, Vrček, N. (2013). Cost effectiveness of commercial computing clouds, Information Systems, 38, pp. 495-508.

5. Cătinean and Cândea, 2013. Characteristics of the Cloud Computing Model as a Disruptive Innovation. Review of International Comparative Management, 14(5), pp. 783-803.

6. Creeger, M. (2009). CTO roundtable: Cloud computing. Communications of the ACM, 52(8), 50-56.

7. DaSilva, C.M., Trkman, P., Desouza, K. and Lindič, J. (2013). Disruptive technologies: A business model perspective on cloud computing. Technology Analysis and Strategic Management, 25(10), pp. 1161-1173

8. Dijkstra, R. (2011) Cloud Computing - A Disruptive New Business Model. Retrieved on November 19, 2014 from http://cloud-computing-economics.com/business-benefits-applications/cloud-computing-disruptivebusiness-model/

9. Etro, F. (2009). The economic impact of cloud computing on business creation, employment and output in Europe. Review of Business and Economics, 54 (2), 179-208. 
10. García-Valls, M., Cucinotta, T., \& Lu, C. (2014). Challenges in real-time virtualization and predictable cloud computing. Journal of Systems Architecture, 60(9), 726. Retrieved from http://ezproxy.fgcu.edu/login?url=http://search.proquest.com/docview/1611654560?accountid=10919

11. Garg, S.K., Versteeg, S., Buyya, R. (2013). A framework for ranking of cloud computing services. Future Generation Computer Systems 29, pp. 1012-1023.

12. Gartner (2006). Press Releases: Gartner Says Eight of Ten Dollars Enterprises Spend on IT is "Dead Money", Retrieved October 22, 2014 from http://www.gartner.com/it/page.jsp?id=497088

13. Ghalimi, I. C. (2010). Benefits of Cloud Computing. An Intalio White Paper. Palo Alto, CA, Intalio, Inc.

14. Grossman, R. (2009). The Case for Cloud Computing. IT Professional, 11 (2), 23-27

15. Gupta, P., Seetharaman, A., and Raj,J.R. (2013). The Usage and Adoption of Cloud Computing by Small and Medium Businesses. International Journal of Information Management 33(5), pp. 861-874.

16. Herbert, L. (2011) The SaaS Market Hits Mainstream: Adoption Highlights 2011. Forrester, 3 May 2011. Retrieved on November 19, 2014 from https://www.forrester.com/The+SaaS+Market+Hits+Mainstream+Adoption+Highlights+2011/fulltext/-/ERES59147

17. IBM (2009). The Benefits of Cloud Computing: A New Era of Responsiveness, Effectiveness and Efficiency in IT Service Delivery. Retrieved on November 19, 2014 at

http://www.informationweek.com/whitepaper/Software/Server-Virtualization/the-benefits-of-cloud-computinga-new-era-of-res-wp1294274216447? articleID=177100033

18. IDC (2013) Press Release: IDC Forecasts Worldwide Public IT Cloud Services Spending to Reach Nearly $\$ 108$ Billion by 2017 as Focus Shifts from Savings to Innovation. Retrieved October 22, 2014, from http://www.idc.com/getdoc.jsp?containerId=prUS24298013

19. Jadhwani, P., Mackinnon, J., \& Elrefal, M. (2009). Cloud Computing-Building a Framework for Successful Transition. GTSI, Northern Virginia. Retrieved on November 19, 2014 from http://www.slideshare.net/jerry0040/cloud-computing-building-a-framework-for-successful-transition-gtsi.

20. Kepes, B. (2011) Cloudonomics: The Economics of Cloud Computing. San Antonio, TX: Rackspace Hosting.

21. Kim, W. (2009). Cloud computing: Today and Tomorrow. Journal of Object Technology, 8 (1) 65-72.)

22. Li, H., Sedayao, J., Hahn-Steichen, J., Jimison, E., Spence, C., \& Chahal, S. (2009). Developing an enterprise cloud computing strategy. Intel Corporation, 1-16. Retrieved on November 19, 2014 from http://www.intel.com/content/dam/doc/white-paper/intel-it-developing-cloud-computing-strategy-paper.pdf.

23. Lin, A, \& Chen, N.C. (2012). Cloud Computing as an Innovation: Perception, Attitude, and Adoption. International Journal of Information Management, 32, pp. 533-540.

24. Lyons, C. (2009). The Urban Cloud: The feasibility of using a Cloud Computing infrastructure for Urban Traffic Control Systems. (Master Dissertation, University of Dublin, 2009).

25. Manyika, J., Chui, M, Bughin, J., Dobbs, R., Bission, P., and Marrs, A. (2013) Disruptive technologies: Advances that will transform life, business, and the global economy, McKinsey Global Institute Report, accessed at (November 24, 2014) http://www.mckinsey.com/ /media/McKinsey/dotcom/Insights\%20and\%20pubs/MGI/Research/Technology\%2 0and\%20Innovation/Disruptive\%20technologies/MGI_Disruptive_technologies_Full_report_May2013.ashx.

26. McAfee, A. (2011). What Every CEO Needs to Know about the Cloud. Harvard Business Review, 89(11), 124132.

27. Marston, S., Li, Z., Bandyopadhyay, S, Zhang, J., and Ghalsasi, A. (2011). Cloud Computing - Business Perspective. Decision Support Systems, 51, pp. 176-189.

28. Mell, P. and Grance, T. (2011). The NIST Definition of Cloud Computing. Recommendations of the National Institute of Standards and Technology. Last retrieved on October 15, 214 from http://csrc.nist.gov/publications/nistpubs/800-145/SP800-145.pdf.

29. Miller, M. (2008). Cloud Computing: Web-based Applications that Change the Way You Work and Collaborate Online. IN, Indianapolis: Que Publisher.

30. Misra, S.C., Mondal, A. (2011). Identification of A Company's Suitability For The Adoption Of Cloud Computing And Modelling Its Corresponding Return On Investment, Mathematical and Computer Modelling, 53 , pp. 504-521.

31. Moens, H., Truyen, E., Walraven, S., Joosen, W., Dhoedt, B., \& De Turck, F. (2014). Cost-effective feature placement of customizable multi-tenant applications in the cloud. Journal of Network and Systems Management, 22(4), 517-558. doi:http://dx.doi.org/10.1007/s10922-013-9265-5 


\section{Issues in Information Systems}

Volume 16, Issue IV, pp. 37-47, 2015

32. Oliveira, T, Thomas, M, Espadanal, M (2014). Assessing the Determinants of Cloud Computing Adoption: An Analysis of the Manufacturing and Services Sectors, Information \& Management 51, pp. 497-510.

33. Oredo, J.O., and Njihia, J. (2014). Challenges of Cloud Computing in Business: Towards New Organizational Competencies. International Journal of Business and Social Science, 5(3), pp. 150-160.

34. Peng, G.C.A., and Gala, C. (2014). Cloud ERP: A new dilemma to modern organizations? The Journal of Computer Information Systems, 54(4), pp. 22-30

35. Perry, R., Hatcher, E., Mahowald, R. P., Hendrick, S. D. (2009, September). Force.com cloud platform drives huge time to market and cost savings. White paper. IDC. Last retrieved on November 19, 2014 from http://thecloud.appirio.com/rs/appirio/images/IDC_Force.com_ROI_Study.pdf.

36. Porter, M. E. (1985). Competitive Advantage: Creating and Sustaining Superior Performance. New York, NY: The Free Press.

37. Pragaladan R, and Suganthi P. (2014). A Study on Challenges of Cloud Computing in Enterprise Perspective. International Journal of Advanced Research in Computer and Communication Engineering, 3(7).

38. Tsai, WT, Sun, X., \& Balasooriya, J. (2010) Service-oriented cloud computing architecture In Information Technology: New Generations (ITNG), 2010 Seventh International Conference on (pp 684-689.). IEEE

39. Weng, F. and Hung, M.C. (2014). Competition and Challenge on Adopting Cloud ERP. International Journal of Innovation, Management and Technology, 5(4), pp. 309-313. 